\title{
The Method of Variant Synthesis of Information and Communication Network Structures on the Basis of the Graph and Set-Theoretical Models
}

\author{
Vadym Mukhin \\ National Technical University of Ukraine "Kiev Polytechnic Institute", Kiev, Ukraine \\ E-mail: v_mukhin@i.ua \\ Yury Romanenkov and Julia Bilokin \\ National Aerospace University "Kharkiv Aviation Institute", Kharkiv, Ukraine \\ E-mail: KhAI.management@ukr.net; juliabelokon84@gmail.com \\ Anton Rohovyi and Anna Kharazii \\ National Technical University "Kharkiv Polytechnic Institute", Kharkiv, Ukraine \\ E-mail: npk.asystems@gmail.com; haraziy@gmail.com
}

Viktor Kosenko

SE "Kharkiv Scientific-Research Institute of Mechanical Engineering Technology", Kharkiv, Ukraine

E-mail: kosvv@ukr.ua

Nataliia Kosenko

O. M. Beketov Kharkiv National University of Urban Economy, Kharkiv, Ukraine

E-mail: kosnatalja@gmail.com

Jun Su

School of Computer Science, Hubei University of Technology, Wuhan, China

Received: 03 July 2017; Accepted: 17 September 2017; Published: 08 November 2017

\begin{abstract}
The subject matter of the article is developing information and communication network (ICN) for critical infrastructure systems (CIS). The aim of the work is to provide high-quality information and telecommunication processes by developing the optimal version of distributing CIS functional tasks and ICN processes to the network nodes. The article deals with following problems: developing a model for mapping the information and technical ICN structures, developing a method for variant synthesis of ITS structural models, a formalized representation of the problem of selecting CIS optimal structure. The methods used are: the system method, the set-theoretic and graphic analytic approaches, methods of hierarchic structures synthesis, optimization methods. The following results were obtained: the use of system approach for formalizing the information processing process in CIS was justified; mapping the ICS functional system into the information and technical one was presented as multilevel graph chain; the generalized representation of graph structures hierarchy was developed for the set of data transmitting tasks; this approach enabled formal representing alternative variants that consider the main links, sequencing, the amount and flows of the processed information among the different
\end{abstract}

structure levels; the scheme of variant synthesis method of ICN models according to graph structures mapping was developed; the problem of selecting optimal ICN structures was formally presented; a complex efficiency criterion for solving problems of optimizing variant synthesis of structures; the problem of optimal synthesis of the structure of the given level factored in resource constraints was formulated. Conclusions. The article deals with such novelty aspects as improving the model of problem of selecting the optimal ICN structure by settheoretic formalization factored in the criterion of maximum intensity of computational resource application, which enabled determining structural links among the major elements considering the decomposition of the model up to the basic elements such as "node" and "task" and the development of a new method of optimal ICN structuring which unlike the existing ones involves the variant synthesis of structures hierarchy and formalizing selection problems on the basis of settheoretic models, which enables providing the efficiency of application of information and technical net resources.

Index Terms - Information and communication network, structure synthesis, graph representation, selecting, 
mapping, set-theoretic model, software.

\section{INTRODUCTION}

With the development of high technologies, the range of high-risk facilities that belong to the class of critical infrastructure systems (CIS) is expanding. For example, thermal, nuclear and hydroelectric power stations, highspeed ground and air transport, defense and space systems. The challenge for such systems is to provide quality information and telecommunications processes. In the context of continuously improving concepts of developing information and communication networks (ICN), in the face of new network technologies, there is the tendency of their "convergence", i.e. amalgamating into more complex structures and technologies. There is the convergence of infomedia different in origin and operation principles.

Despite the rapid development of physical and channel-level technologies, the full potential of ICN can be realized only due to effective managing available network resources in the face of increasing demands for the operability of information exchange. This determines the necessity of searching new approaches to determining the physical and functional structures of the network.

\section{Problem Analysis and Setting the Problem}

When building distributed and local information and communication networks, there is a number of unresolved problems which are complex scientific and technical issues. Considering the ICN hardware and software these problems can be grouped to:

- develop a reliable ICN on the basis of available hardware and software that now consist of isolated and unequal components;

- turn to promising technical and software tools step by step.

At the first stage, when installing software complexes on separate ICN fragments, it is necessary to distribute CIS functional tasks to the nodes of the base fragment, taking into account the heterogeneity of the nodes, the heterogeneity and inequality of hardware and software. It is necessary to keep in mind that the requirements of operability, reliability, continuity and completeness of information for these systems are of primary importance. [1]

Many publications deal with the analysis and synthesis of ICN [2 - 7]. The classical mathematical models based on the results of graph theory and the theory of mass service [3] do not take into account the dependence of net structure characteristics on the parameters of applied problems that are solved in a networked environment, which leads to a loss of accuracy in the results of modelling.

The analysis of the literature showed that the majority of the mathematical models that assume the operation of software complexes in a multiservice network environment do not take into account the heterogeneity of the basic hardware and software support tools of the ICN [6-9].

One of the promising areas of ICN development is the service-oriented approach that enables investigating the processes of information exchange among the network nodes involved in solving various functional tasks and supporting various information processes. This approach enables more adequate modelling of data flows in multiservice ICN. However, the formalization presenting data streams in this approach is still insufficient and is limited to modelling individual tasks and aspects of ICN operation $[10,11]$.

Therefore, the purpose of this article is to develop a formalized model and a method for synthesizing ICN structures that enables developing an optimal version of distributing CIS functional problems and ICN processes to the nodes of the basic fragment of the network.

\section{PROBLEM SOLVING}

A large number of elements of CIS subsystems and the functions they perform, a high degree of elements interconnection, the complexity of algorithms for selecting particular actions for controlling real-time processes, large amounts of processed information determine ICN that enables CIS operating as a complex system [8]. The synthesis of the structure of a complex system requires developing the following formalized models;

a) he models of the controlled system structure for determining the optimal composition and interrelations of the systems elements, the optimal partitioning of the set of controlled objects into separate subsets that have the specified characteristics of the relations;

b) the model of the control system structure for solving the problems of variant choice: a number of levels and subsystems, the organizational hierarchy, for determining the principles of management organization and the optimal distribution of performed functions among different system components;

c) the model of the structure of data transmission and processing systems factored in the composition of the hardware and software of the telecommunications network.

When developing a model for the hardware and software structure, it is necessary to consider the following points $[8,12,13]$ :

- determining a set of ICN nodes and connections among them;

- distributing tasks assigned to the technical means of ICN to the levels and nodes of the system;

- selecting ICN technical means that provide the effective solution of CIS tasks. 
The above problems of the synthesis of models of ICN structure are closely related to the tasks of optimizing its functioning: to determine the composition of nodes, that is optimal in reference to the complex functional of efficiency, as well as the structure of the interrelations among them for the given set of CIS functions [15].

In accordance with the system approach for building the model of information processing in ICN, it is necessary to determine the management objectives and functional tasks in CIS, information and communication processes for completing tasks, dataware and software, to distribute tasks, processes and support elements to the nodes of the system and, in accordance with this, to determine the complex of technical means.

If there are some problems of heavy load for some elements of the system structure, it is necessary to take into account the rules of their functioning. These rules are determined while modelling the system since the distribution of functions and relationships in the system depends on them.

When constructing a model of the information processing process, the following selection problems should be solved:

- $\quad$ selecting typical subsystems, tasks, CIS modules for determining functional and information tasks, system nodes and their interrelations;

- $\quad$ selecting options for building ICN nodes and their location;

- $\quad$ selecting options for performing various types of CIS functional tasks;

- $\quad$ selecting options for ICN constructing factored in mapping the set of CIS functional tasks and information processes for their implementation in a set of interconnected ICN nodes;

- selecting variants that are optimal in reference to the criterion of efficiency for constructing CIS structure.

To formalize the data for selecting problems the graph and set-theoretical representation is suggested. Thus, the alternative-graph model of the process of information processing is the basis for describing the process of synthesizing the ICN structure and software.

Let $\mathrm{G}_{\mathrm{S}}=\left(\mathrm{S}, \Gamma_{\mathrm{S}}\right)$ graph define a set of interrelated functional problems of a distributed CIS, where $S$ is a set of graph vertices that correspond to individual problems, $\Gamma_{\mathrm{S}}$ is a set of arcs that show the relationships among them. For $s_{i} \in S, i=\overline{1, n}$ the graph of the implementation of the tasks of information and communication support $\mathrm{G}_{\mathrm{I}}=\left(\mathrm{I}, \Gamma_{\mathrm{I}}\right)$ is built. Thus, mapping the set of vertices of the graph $s_{i} \in S, i=\overline{1, n}$ in the set of vertices $\mathrm{i}_{\mathrm{j}} \in \mathrm{I}, \mathrm{j}=\overline{1, \mathrm{~m}}, \mathrm{G}_{\mathrm{S}} \rightarrow \mathrm{G}_{\mathrm{I}}$ is obtained. This mapping implements the functional structure (FS) of the CIS and ICN complex.

The tasks of information and communication support are solved with the help of a set of system and application software. Accordingly, at the next level, for each element $\mathrm{i} \in \mathrm{I}$ there is a graph $\mathrm{G}_{\mathrm{P}}=\left(\mathrm{P}, \Gamma_{\mathrm{P}}\right)$ of a set of elements of the used software $(\mathrm{SW}) \mathrm{p}_{\mathrm{k}} \in \mathrm{P}, \mathrm{k}=\overline{1,1} ; \Gamma_{\mathrm{P}}$ is a set of arcs that show the relationships between them. Mapping the set of vertices of the graph $i_{j} \in I, j=\overline{1, m}$ in a set of vertices $\mathrm{p}_{\mathrm{k}} \in \mathrm{P}, \mathrm{k}=\overline{1,1}, \mathrm{G}_{\mathrm{I}} \rightarrow \mathrm{G}_{\mathrm{P}}$ is obtained.

The graph of a set of information support elements (specialized and local databases) is denoted as $G_{B}=\left(B, \Gamma_{B}\right)$, where $B$ is a set of vertices of the graph corresponding to the elements of information support; $\Gamma_{\mathrm{B}}$ is a set of arcs reflecting data relationship. Mapping a set of vertices of the graph $\mathrm{p}_{\mathrm{k}} \in \mathrm{P}, \mathrm{k}=\overline{1,1}$ in a set of vertices $b_{m} \in B, m=\overline{1, f}, G_{P} \rightarrow G_{B}$ of functional structure in ICN information structure is obtained. This mapping implements ICN information structure (IS).

Thus, mapping

$$
\left(\mathrm{G}_{\mathrm{S}} \rightarrow \mathrm{G}_{\mathrm{I}}\right)_{\mathrm{FS}} \rightarrow\left(\mathrm{G}_{\mathrm{P}} \rightarrow \mathrm{G}_{\mathrm{B}}\right)_{\mathrm{IS}}
$$

is formally represented as a multilevel chain of graphs mapping.

To implement information and communication tasks, ICN technical structure should be developed. Graphs $\mathrm{G}_{\mathrm{U}}=\left(\mathrm{U}, \Gamma_{\mathrm{U}}\right)$ that are the variants of realization of the local networks structure are defined as ICN nodes, where $\mathrm{U}$ is a set of vertices of the graph corresponding to the nodes of the network; $\Gamma_{U}$ is a set of arcs reflecting the system of switching nodes. Mapping a set of vertices of the graph $i_{j} \in I, j=\overline{1, m}$ in a set of vertices $\mathrm{u}_{\mathrm{c}} \in \mathrm{U}, \mathrm{c}=\overline{1, \mathrm{~d}}, \mathrm{G}_{\mathrm{I}} \rightarrow \mathrm{G}_{\mathrm{U}}$ is obtained.

For a variety of options for ICN technical structure a variety of options for data transmission, that is traffic management, [16, 17] should be determined. Graph $\mathrm{G}_{\mathrm{T}}=\left(\mathrm{T}, \Gamma_{\mathrm{T}}\right)$ i.e. the options for implementing data flows as information links, where $\mathrm{T}$ is a set of vertices of the graph corresponding to the nodes of the network, and $\mathrm{T} \subset \mathrm{U} ; \Gamma_{\mathrm{U}}$ is a set of arcs representing the system of knot commutation, $\Gamma_{\mathrm{T}} \subset \Gamma_{\mathrm{U}}$. Mapping the set of vertices of the graph $\mathrm{u}_{\mathrm{c}} \in \mathrm{U}, \mathrm{c}=\overline{1, \mathrm{~d}}$ in a set of vertices $\mathrm{t}_{\mathrm{h}} \in \mathrm{T}, \mathrm{h}=\overline{1, \mathrm{z}}, \mathrm{G}_{\mathrm{U}} \rightarrow \mathrm{G}_{\mathrm{T}}$ is obtained. This mapping implements ICN technical structure (TS).

Mapping ICN functional structure in the information and technical one is represented as a multilevel chain of graphs:

$$
\left(\mathrm{G}_{\mathrm{S}} \rightarrow \mathrm{G}_{\mathrm{I}}\right)_{\mathrm{FS}} \rightarrow\left\langle\begin{array}{l}
\left(\mathrm{G}_{\mathrm{P}} \rightarrow \mathrm{G}_{\mathrm{B}}\right)_{\mathrm{IS}} \\
\left(\mathrm{G}_{\mathrm{U}} \rightarrow \mathrm{G}_{\mathrm{T}}\right)_{\mathrm{TS}}
\end{array}\right.
$$

After the synthesis of the options for ICN technical structure, the software and information support should be assigned to the nodes of the network factored in the channels of information interaction. The result can be 
represented as a mutual mapping of the following sets:

$\mathrm{G}_{\mathrm{P}} \leftrightarrow \mathrm{G}_{\mathrm{U}}$ is options for assigning application programs to network nodes for solving specific functional tasks;

$\mathrm{G}_{\mathrm{B}} \leftrightarrow \mathrm{G}_{\mathrm{T}}$ is definition of data flows at a variety of information relationships.

Taking into account the mappings mentioned above, which can be generally represented by functions $\varphi 1 \ldots \varphi 6$, graph model of the synthesis of ICN structures looks as follows:

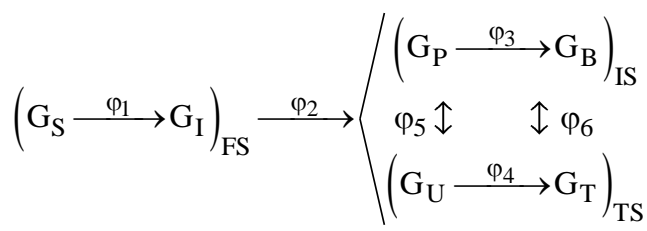

In particular, for a complex of data transfer tasks, a generalized representation of the graph structures hierarchy is shown in Figure 1. Here, set S represents the structure of probable realizations of CIS basic functional problems. Consequently, for each variant of implementation $\mathrm{S}$, different variants of numerous dataware and software tasks, application programs and databases, as well as ICN nodes and data transmission facilities are considered.
According to the system approach, the scheme of the method of variant synthesis of ITS structural models as described by mapping graph structures (Fig. 1) is schematically shown in Fig. 2.

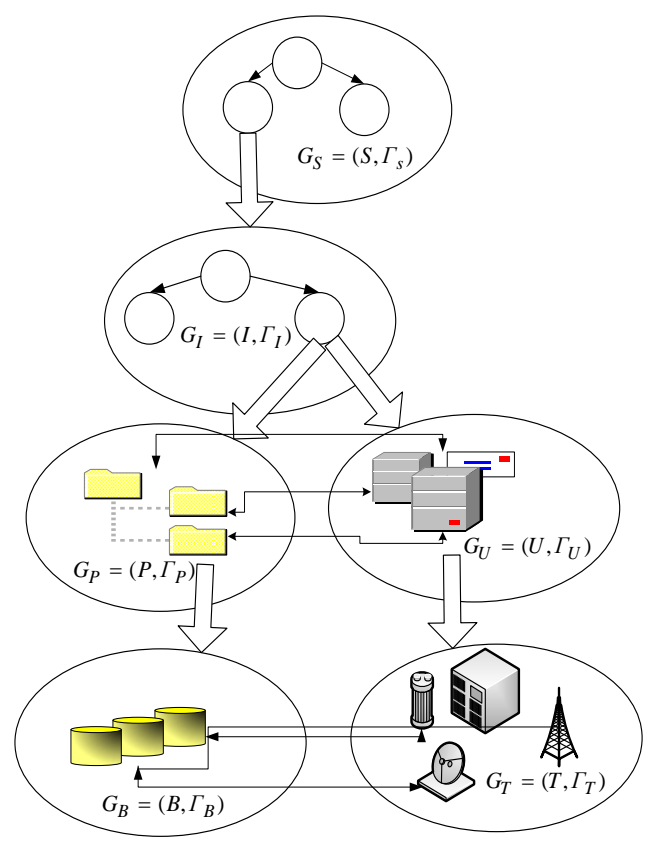

Fig.1. Generalized representation of the hierarchy of ICN graph structures.

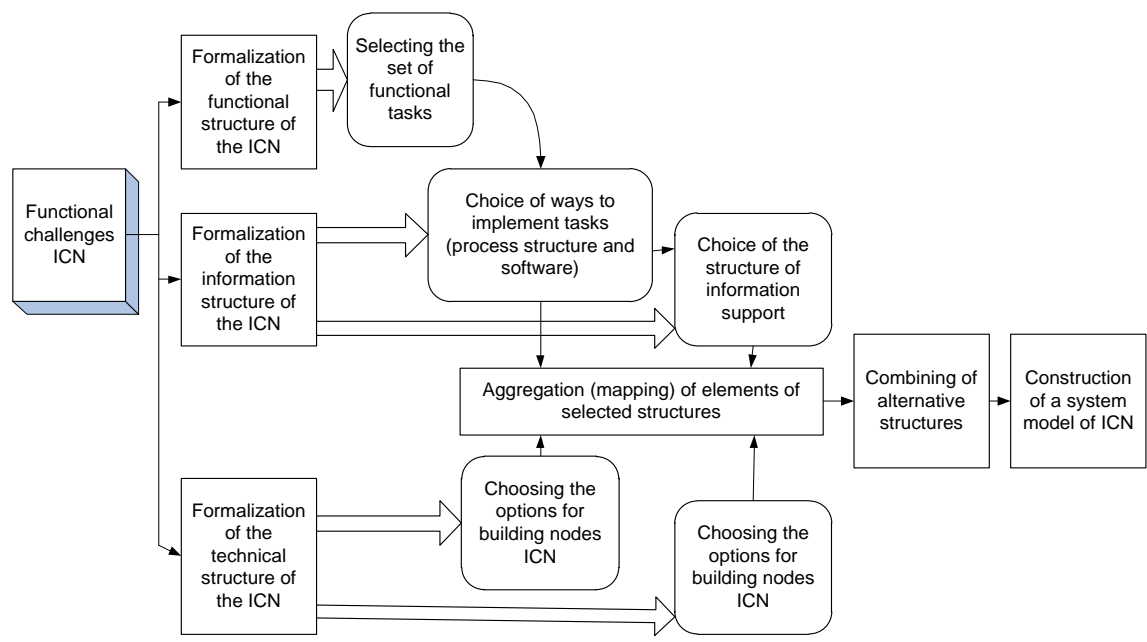

Fig.2. Scheme of the method of variant synthesis of ICN Structural models

It should be noted that, the relationships that reflect the sequence, amounts or flows of transmitted information are considered while formalizing the relationships between tasks or stages.

The system approach assumes that when the formalization of the process of information processing in a complex system changes to the model of its functioning, the following stages should be necessarily performed:

- modelling all admissible variants of initial data allocation;
- $\quad$ modelling all variants of task placement among the system nodes;

- distinguishing and analyzing partially isolated components of the system and constructing appropriate models.

According to the above scheme of the method the initial sets are represented in the mentioned models by the elements of the graph structures S, I, P, B, U, T; while mappings that determine the relationships of the structures as: 


$$
\begin{aligned}
& \varphi_{1}: \mathrm{G}_{\mathrm{S}} \rightarrow \mathrm{G}_{\mathrm{I}} \\
& \varphi_{2}: \mathrm{G}_{\mathrm{I}} \rightarrow\left(\mathrm{G}_{\mathrm{P}}, \mathrm{G}_{\mathrm{U}}\right) \\
& \varphi_{3}: \mathrm{G}_{\mathrm{P}} \rightarrow \mathrm{G}_{\mathrm{B}} \\
& \varphi_{4}: \mathrm{G}_{\mathrm{U}} \rightarrow \mathrm{G}_{\mathrm{T}} \\
& \varphi_{5}: \mathrm{G}_{\mathrm{P}} \leftrightarrow \mathrm{G}_{\mathrm{U}} \\
& \varphi_{6}: \mathrm{G}_{\mathrm{B}} \leftrightarrow \mathrm{G}_{\mathrm{T}}
\end{aligned}
$$

Considering these mappings, the problem of selecting ICN optimal structures can be formally represented.

The elements of the graph structures I,J,L, M,P considered above are greater and include tasks, software, data, technical objects, communication facilities, etc. However, the above graph of alternative structures assumes such hierarchical sequence of the elements of structures where the subsets of homogeneous objects are detailed at the same level of hierarchy.

In such a case the correspondence which is important for the synthesis of structures should be set up among them, considering one of the two options:

- distinguishing such a variant (among the set of admissible variants) that will enable achieving the required properties in the context of specified criteria for optimality grounding on a set of required properties of the structure;

- analyzing the probability of achieving ICN required properties grounding on characteristics of the structure.

In consideration of the foregoing, ICN information structure can be determined by a set of the following parameters:

- $\quad \mathrm{N}$, that is a number of working users;

- M, that is the amount of nodes used;
- $\quad$ D, that is a number of system applications being used;

- $\quad$ L, that is the amount of tasks being solved;

- $\quad \mathrm{R}$, that is a number of databanks being used.

Besides, it is necessary to determine:

a) Z, that is a data tuple which describes tasks $Z$ and sets the matrix lines which describe the interrelations of the tasks:

- $\quad$ with system applications - P,

- with databanks - D,

- $\quad$ with users - U;

b) the sequence of executing system applications by specific tasks - Wk;

c) a set of descriptions of data amounts -Akm, which are necessary for system applications while using them by specific tasks, and consist of matrix lines of data amounts $\mathrm{Vk}$ and $\mathrm{Bk}$;

d) the matrix of system application assignment to the net nodes $-\mathrm{G}$;

e) the matrix of connecting users to the nodes $-\mathrm{H}$;

f) the matrix of databases allocation to the nodes $-\mathrm{S}$.

This set definitely determines the information structure of an information and communication net.

Let us specify a set of parameters that determine the net information structure as SI. Thus, we have:

$$
\begin{gathered}
\mathrm{SI}=\left\{\mathrm{N}, \mathrm{M}, \mathrm{D}, \mathrm{L}, \mathrm{R}, \mathrm{S}_{\mathrm{i}}, \mathrm{A}_{\mathrm{km}}, \mathrm{G}, \mathrm{H}, \mathrm{S}\right\}, \\
\mathrm{S}_{\mathrm{i}}=\left\{\mathrm{p}_{\mathrm{i}}, \mathrm{d}_{\mathrm{i}}, \mathrm{u}_{\mathrm{i}}, \mathrm{W}_{\mathrm{i}}\right\}, \\
\mathrm{A}_{\mathrm{km}}=\left\{\mathrm{v}_{\mathrm{km}}, \mathrm{b}_{\mathrm{km}}\right\} .
\end{gathered}
$$

The major elements of the information structure and their parameters are shown in Fig. 3.

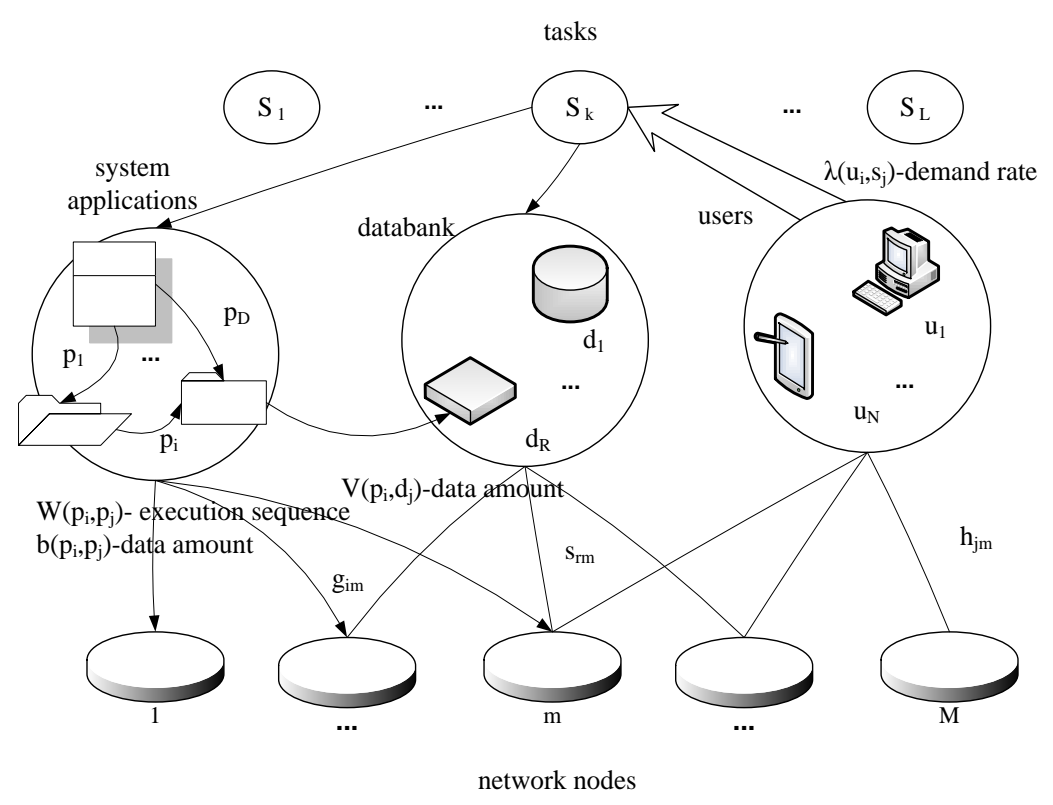

Fig.3. The diagram of the major element and parameters of the model of ICN information structure 
It should be noted that if system applications and databanks are compared according to their allocation to the net nodes (the rules of developing $\mathrm{G}$ and $\mathrm{S}$ matrices), databanks can be considered as system applications in the context of theoretical studies of the network. This approach enables simplifying the obtained data greatly and making them more descriptive.

Keeping in mind that all possible variants of the information structure of the network can be described in the foregoing manner, it is necessary to formalize the procedure for selecting the optimal structure, which is a sequence of particular selection problems.

Let a set of variants of ICN representation be denoted as:

$$
\mathrm{S}=\left(\mathrm{S}^{0}, \mathrm{~S}^{1}\right), \mathrm{S}^{1}=\left\{\mathrm{s}_{\mathrm{ik}}\right\}, \mathrm{i}=\overline{1, \mathrm{~m}}, \mathrm{k}=\overline{1, \mathrm{~m}}
$$

where $\mathrm{S}^{0}$ is the initial state of the model, which is determined by the functional tasks of the entire system;

$\mathrm{S}_{\mathrm{ik}}$ is the state of the model of ICN structure at the $\mathrm{k}^{\text {th }}$ level of the hierarchy after the solution of the $i^{\text {th }}$ selection problem.

Let a set of modelling steps be determined as:

$$
\mathrm{H}=\left(\mathrm{H}^{0}, \mathrm{H}^{1}\right), \mathrm{H}^{1}=\left\{\mathrm{h}_{\mathrm{ik}}\right\}, \mathrm{i}=\overline{1, \mathrm{~m}}, \mathrm{k}=\overline{1, \mathrm{~m}},
$$

where $\mathrm{H}^{0}$ is the action necessary to change solving the tasks of CIS functioning to solving the tasks of ICN functioning;

$\mathrm{h}_{\mathrm{ik}}$ is a set of steps for modelling the solution of the $\mathrm{i}^{\text {th }}$ task at the $\mathrm{k}^{\text {th }}$, that represent such series of steps which result in the transition to the $(\mathrm{k}+1)^{\text {th }}$ level of the hierarchy of the object structure being modelled.

Then the following relations are correct:

$$
\begin{aligned}
& {\left[\mathrm{s}_{\mathrm{i}(\mathrm{k}-1)}, \mathrm{s}\left(\mathrm{h}_{\mathrm{ik}}\right)\right] \Rightarrow \mathrm{s}_{\mathrm{ik}} ;} \\
& {\left[\mathrm{h}_{\mathrm{i}(\mathrm{k}-1)}, \mathrm{h}\left(\mathrm{s}_{\mathrm{ik}}\right)\right] \Rightarrow \mathrm{h}_{\mathrm{ik}},}
\end{aligned}
$$

where $s\left(h_{i k}\right)$ is additional data for the model obtained by performing step $\mathrm{h}_{\mathrm{ik}}$,

$\mathrm{h}\left(\mathrm{s}_{\mathrm{ik}}\right)$ is the step selected according to the state $\mathrm{s}_{\mathrm{ik}}$.

To select step $h_{i k}$ all the states of the model of the complex $\left\{\mathrm{s}_{\mathrm{ik}}\right\}, \mathrm{i}=\overline{1, \mathrm{~m}}, \mathrm{k}=\overline{1, \mathrm{~m}}$ should be built.

Let the procedure for selecting the step at the $\mathrm{k}^{\text {th }}$ level be denoted by $\mathrm{V}_{\mathrm{k}}$. Then $\mathrm{s}_{\mathrm{k}} \stackrel{\mathrm{V}_{\mathrm{k}}}{\longrightarrow} \mathrm{h}_{\mathrm{k}}$, where $\mathrm{s}_{\mathrm{k}} \in \mathrm{S}$ is a set of admissible states of the model at the level $\mathrm{k}$. If step $h_{k}$ is not appropriate, the procedure of re-selecting is necessary. This procedure will be denoted by $\mathrm{V}_{\mathrm{k}} *$.
Then $\mathrm{s}_{\mathrm{k}} \stackrel{\mathrm{V}_{\mathrm{k}}{ }^{*}}{\longrightarrow} \mathrm{h}_{\mathrm{j}}$, where $\mathrm{j}=\overline{1, \mathrm{k}}, \mathrm{k} \leq \mathrm{m}$. Combining the expressions obtained, the process of selecting the step can be denoted by the expression:

$$
\mathrm{h}_{\mathrm{j}}=\left\{\begin{array}{l}
\mathrm{V}_{\mathrm{j}}\left(\mathrm{s}_{\mathrm{j}}\right), \text { если } \mathrm{V}_{\mathrm{k}} *\left(\mathrm{~s}_{\mathrm{k}}\right)=\mathrm{j}, \mathrm{j}<\mathrm{k} \\
\mathrm{V}_{\mathrm{k}}\left(\mathrm{s}_{\mathrm{k}}\right), \text { если } \mathrm{V}_{\mathrm{k}} *\left(\mathrm{~s}_{\mathrm{k}}\right)=\mathrm{k}
\end{array}\right.
$$

Subset S" of the end states of the system model is selected in set $S$. Then subset $S^{\prime \prime}$ is split into two more subsets of the second level:

$$
S^{\prime \prime}=\left(S_{+}, S_{-}\right)
$$

where $\mathrm{S}_{+}$is a subset of the end states satisfying CIS safety conditions;

$\mathrm{S}_{\text {_- }}$ is a subset of the end states that are characterized by a significant level of risk.

The $\mathrm{i}^{\text {th }}$ selection problem while synthesizing ICN structures factored in the state of the model is denoted as the tuple

$$
\mathrm{Z}_{\mathrm{i}}=\left\langle\mathrm{S}_{\mathrm{i}}, \mathrm{H}_{\mathrm{i}}, \mathrm{V}, \mathrm{W}, \mathrm{i}\right\rangle, \mathrm{S}_{\mathrm{i}} \subset \mathrm{S}_{+}{ }, \mathrm{H}_{\mathrm{i}} \subset \mathrm{H}, \mathrm{i}=\overline{1, \mathrm{~m}} .
$$

In this case, the initial selection problem is defined as:

$$
\mathrm{Z}_{0}=\left\langle\mathrm{S}^{0}, \mathrm{H}^{0}, \mathrm{~V}, \mathrm{~W}, 0\right\rangle
$$

Then the variant synthesis of structures lies in the sequential transition from the solution of problem $Z_{0}$ to the solution of a certain problem $\mathrm{Z}_{\mathrm{m}}$, when the model changes to state $S^{m} \in S^{\prime \prime}$. In this case, if $S^{m} \in S^{\prime \prime}$, the execution of the sequence of states $S^{0}, S^{1}, \ldots, S^{m}$ is a global task of synthesizing the structures of the target network. Let $\mathrm{Z}_{\mathrm{n}}^{\prime}$ be its solution, then the set of all such solutions is:

$$
\mathrm{Z}^{\prime}=\left\{\mathrm{Z}_{\mathrm{n}}^{\prime}\right\}, \mathrm{n}=\overline{1, \mathrm{~m}}
$$

The specified set should be estimated according to the complex criterion of ICN efficiency. Then the formal model of the problem of optimizing the variant synthesis of structures is represented by the tuple

$$
\Psi=\left\langle Z_{0}, \mathrm{Z}, \mathrm{Z}^{\prime}, \mathrm{F}\right\rangle
$$

where $\mathrm{F}$ is the complex efficiency criterion.

Let us consider ICN structure at the level of the processes and tasks of applied software (set P). Within model $\mathrm{M}$, the sets of tasks that must be performed by the ith elements will be denoted as $\mathrm{P}^{\mathrm{i}}=\mathrm{p}_{\mathrm{k}}^{\mathrm{i}}, \mathrm{k}=\overline{1, \mathrm{l}} ; \mathrm{i}=\overline{1, \mathrm{~m}}, \mathrm{P}^{\mathrm{i}} \in \mathrm{P}$. 
Let us assume that the execution of each process from $\mathrm{p}_{\mathrm{k}}^{\mathrm{i}} \in \mathrm{P}^{\mathrm{i}}$ requires the consumption of information and computing resource $\mathrm{M}_{\mathrm{k}}^{\mathrm{i}}$ that is subject to optimization and represented as a hierarchy subordinate to applied processes. To consider repeatedly performed processes, the coefficient $a_{k}^{i}$ is introduced. Then the process $p_{k}^{i}$ will be executed while consuming information and computing resources in the amount of $a_{k}^{i} M_{k}^{i}$ that is subject to optimization.

Pair $\left(P_{j}^{*}, j\right)$ is called the state of the $j^{\text {th }}$ level, where $\mathrm{P}_{\mathrm{j}}^{*} \subset \mathrm{P}^{\mathrm{i}} \subset \mathrm{P}$ is a subset of the $\mathrm{i}^{\text {th }}$ level tasks that can be performed together without exceeding the level of magnitude $M^{i}$. Let $M^{i}\left(P_{j}^{*}\right)$ be the information and computational resource consumption in the state with number $\mathrm{j}$.

Then

$$
\Delta_{j}^{i}=M^{i}-M^{i}\left(P_{j}^{*}\right) \geq 0
$$

The process of synthesizing the ith level structure consists of changing the sequence of states $\left(\mathrm{P}_{1}^{*}, 1\right),\left(\mathrm{P}_{2}^{*}, 2\right), \ldots,\left(\mathrm{P}_{\mathrm{j}}^{*}, \mathrm{j}_{\mathrm{i}}\right)$, which is carried out in such a way that the optimization problem according to the local criterion Fi is solved.

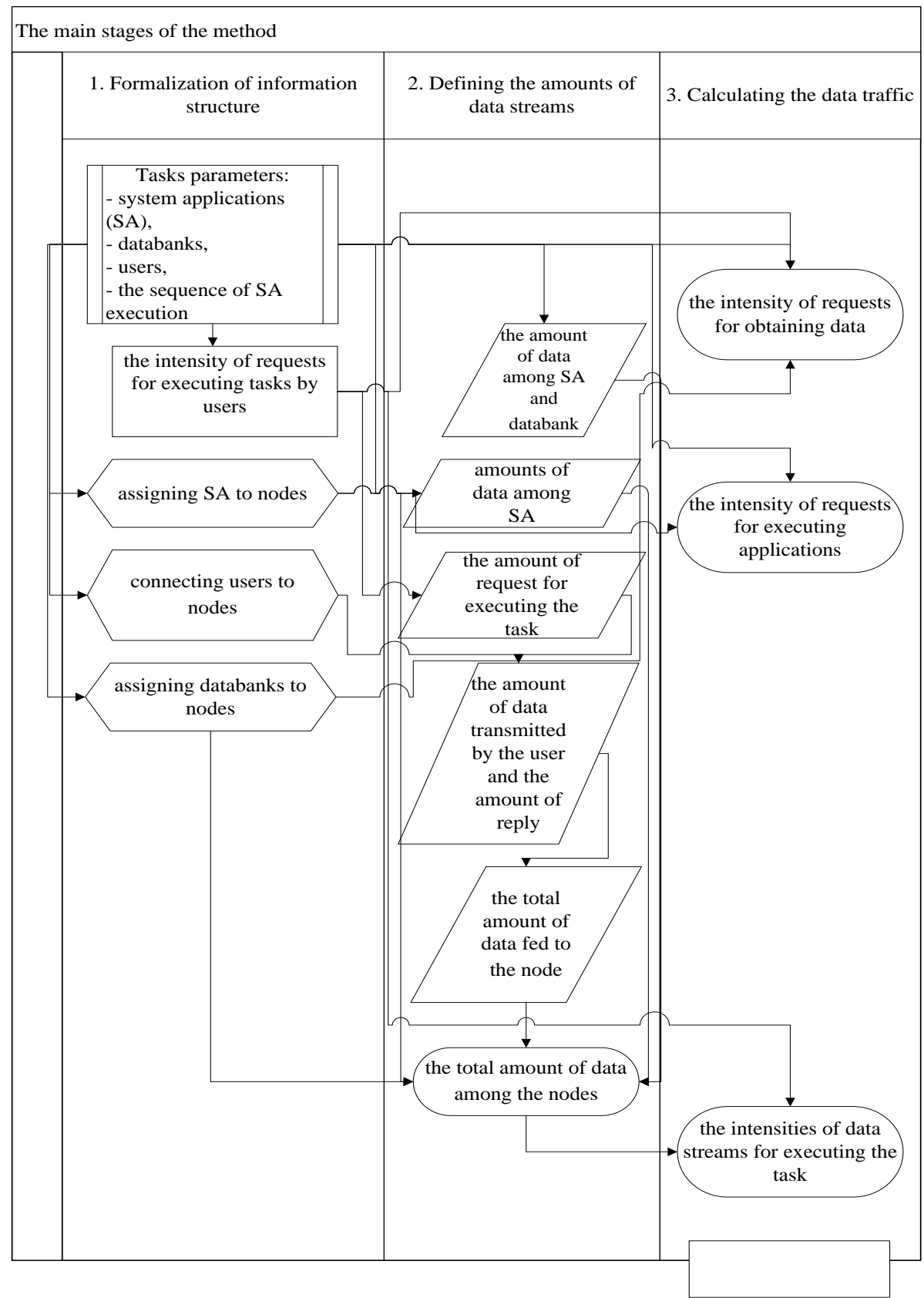

Fig.4. Scheme of the method of determining the parameters of data flows in the context of the fixed information structure of the net 
However, it is necessary to take in account a number of external constraints that arise during the execution of the process $\mathrm{p}_{\mathrm{j}}^{\mathrm{i}} \in \mathrm{P}_{\mathrm{j}}^{*}$, which are denoted by $\mathrm{D}^{\mathrm{i}}\left(\mathrm{P}_{\mathrm{j}}^{*}\right)$. In particular, vector $\mathrm{D}^{\mathrm{i}}\left(\mathrm{P}_{\mathrm{j}}^{*}\right)$ may include resource component $\mathrm{M}^{\mathrm{i}}$. Then the problem of optimal synthesis of the ith level structure factored in external constraints is defined as follows: to find a way to form sets $\mathrm{P}_{1}^{*}, \mathrm{P}_{2}^{*}, \ldots, \mathrm{P}_{\mathrm{j}}^{*}$ in the model environment $\Psi$, where

$$
\sum_{\mathrm{j}=1}^{\mathrm{l}_{\mathrm{i}}} \Delta_{\mathrm{j}}^{\mathrm{i}} \rightarrow \min , \quad \mathrm{D}^{\mathrm{i}}\left(\mathrm{P}_{\mathrm{j}}^{*}\right) \leq \mathrm{D}^{\mathrm{i}}, \mathrm{j}=\overline{1,1}
$$

The formalization of selecting optimal structure of a multilevel ICN that enables CIS functioning makes construction of corresponding ICN models possible.

After the optimal alternative of the net information structure has been selected, the parameters of data flows should be assigned among its nodes while solving a particular task. These intensities are determined by the intensity of the task execution considering all the users of the net (system). It is believed that each application which is used while executing the task is run once only.

The method of determining the parameters of data flows in the context of fixed information structure of the net is shown in Fig.4. The method suggested enables assigning the intensities of data flows to the system nodes. Under these conditions the types of interrelations among the elements of the information structure of thenet and its source data about the amounts of transmitted information are given in Table 1 .

Table 1. Parameters of the amounts of transmitted data among the elements of ICN information structure

\begin{tabular}{|l|c|c|}
\hline \multicolumn{1}{|c|}{ Parameters } & $\begin{array}{c}\text { Means of } \\
\text { communication }\end{array}$ & Symbols \\
\hline $\begin{array}{l}\text { The amount of data } \\
\text { transmitted by the } \\
\text { user }\end{array}$ & user - nodes & $\begin{array}{c}\mu_{\mathrm{m}}, \\
(\mathrm{m}=1,2, \ldots, \mathrm{D})\end{array}$ \\
\hline $\begin{array}{l}\text { The amount of task } \\
\text { demand }\end{array}$ & user - task & $\begin{array}{c}\varphi_{0 \mathrm{mk}}, \\
(\mathrm{k}=1,2, \ldots, \mathrm{L}, \\
\mathrm{m}=1,2, \ldots, \mathrm{D})\end{array}$ \\
\hline $\begin{array}{l}\text { The amount of } \\
\text { responses to the user }\end{array}$ & task- user & $\begin{array}{c}\varphi_{1 \mathrm{mk}}, \\
(\mathrm{k}=1,2, \ldots, \mathrm{L}, \\
\mathrm{m}=1,2, \ldots, \mathrm{D})\end{array}$ \\
\hline $\begin{array}{l}\text { Total amount of data } \\
\text { transmitted by users }\end{array}$ & user - node & $\mathrm{v}_{\mathrm{j}}^{0},(\mathrm{j}=1,2, \ldots, \mathrm{M})$ \\
\hline $\begin{array}{l}\text { Total amount of data } \\
\text { received by users }\end{array}$ & node - user & $\mathrm{v}_{\mathrm{j}}^{1},(\mathrm{j}=1,2, \ldots, \mathrm{M})$ \\
\hline $\begin{array}{l}\text { Total amount of data } \\
\text { fed to the nod while } \\
\text { executing the task }\end{array}$ & task - node & $\pi_{\mathrm{j}}^{0},(\mathrm{j}=1,2, \ldots, \mathrm{M})$ \\
\hline
\end{tabular}

\section{CONCLUSION}

To formalize the process of processing information in CIS the application of the system approach is justified. This approach enabled distinguishing the structural components of selecting structures in ICN environment and to construct a hierarchical graph of alternative formalization that considers the main relationships that reflect the sequence, amounts and flows of information that is processed among different levels of structures. The construction of this graph is the basis for developing the method for building the optimal structure of ICN.

The means for formal description of ICN information structure were developed; these means definitely determine the parameters of applications and their interrelationship. The basis is the complex mathematical model whose components describe the information structure, data flows and the technical structure of the net. The major parameters of the model of the net information structure which is the basis for developing the models of data flows are described.

The article deals with the following novelty aspects:

- $\quad$ improving the model of the problem of selecting ICN optimal structure, by means of set-theoretical formalization considering the criterion of the maximum intensity of using the computational resource, which enabled determining the structural links between the basic elements factored in the decomposition of the model to the basic elements "node" and "task";

- developing a new method of building ICN optimal structure which, unlike the existing ones, assumes the variant synthesis of hierarchy of structures and formalization of selection problems on the basis of set-theoretic models, which makes it possible to ensure the efficient use of information and technical resources of the network.

The formalized model of ICN information structure helped determine the methods of computing a set of parameters and characteristics that describe in particular: the intensities of flows of users' requests, the intensity of data flows among information nodes, loading to the net nodes, the intensities of flows of request to the databank.

\section{REFERENCES}

[1] Zhenbing $\mathrm{Hu}$, Vadym Mukhin, Yaroslav Kornaga, Yaroslav Lavrenko, Oksana Herasymenko,"Distributed Computer System Resources Control Mechanism Based on Network-Centric Approach", International Journal of Intelligent Systems and Applications(IJISA), Vol.9, No.7, pp.41-51, 2017. DOI: 10.5815/ijisa.2017.07.05

[2] D. V. Ageev, A. A. Ignatenko, A. N. Kopylev, "Method for Determination of Flow Parameters in Different Parts of Multiservice Telecommunications Network, Taking Into Account the Effect of Self-Similarity", Electronic scientific specialized edition - journal "Problems of Telecommunications", No.3 (5), pp. 18-37, 2011. Available at: http://pt.journal.kh.ua/2011/3/1/113_ageyev_ method.pdf (last accessed March 23, 2017).

[3] Yu. Losev, K. Ruccas, "The Comparative Analysis of the Mathematical Device of Modelling of Telecommunication Networks", Information Processing Systems, Kharkiv: Ivan Kozhedub Kharkiv National Air Force University, No. 8 (66), pp. 55-60, 2007.

[4] Hamed Dinari,"A Survey on Graph Queries Processing: 
Techniques and Methods", International Journal of Computer Network and Information Security(IJCNIS), Vol.9, No.4, pp. 48-56, 2017.DOI: 10.5815/ijcnis.2017.04.06

[5] Ayodeji J. Akande, Colin Fidge, Ernest Foo,"Limitations of Passively Mapping Logical Network Topologies", International Journal of Computer Network and Information Security(IJCNIS), Vol.9, No.2, pp.1-11, 2017.DOI: 10.5815/ijcnis.2017.02.01

[6] E. Gelenbe, G. Pujolle, Analysis and Synthesis of Computer Systems (2nd Edition), Advances in Computer Science and Engineering: Texts. Vol. 4, 309 p., 2010.

[7] RFC 1122 - Requirements for Internet Hosts Communication Layers. Available at: http://rfc2.ru/1122.rfc (last accessed March 23, 2017).

[8] N.S. Marder, Modern Telecommunications, Moscow: IRIAS, 255 p., 2006.

[9] G. A. Kuchuk, R. P. Gakhov, A. A. Pashnev, Infocommunication Resources Management, Moscow: Fizmatlit, 220 p., 2006.

[10] I Pepelnjak, EIGRP Network Design Solutions: The Definitive Resource for EIGRP Design, Deployment and Operation [Text], CiscoPress, 384 p., 2000.

[11] C. Paulsen, J. Boyens, Summary of the Workshop on Information and Communication Technologies Supply Chain Risk Management, National Institute of Standarts and Technology, 21 p., 2012.

[12] G. A. Kuchuk, A. A. Pashnev, "Classification of Control Tasks for Multi-Service Networks of Distributed Information-Control Systems for Critical Applications", Problems of Management of the Uniform State Civil Protection System: Collection of Materials of the NPC, 4.04.2007, Kharkiv: Ministry of Emergencies, URZU, pp. 104-106, 2007.

[13] V. G. Olifer, N. A. Olifer, (2012), Computer Networks. Principles, Technologies, Protocols, (4th Edition), St. Petersburg: Piter, 943 p., 2012.

[14] Zhengbing $\mathrm{Hu}$, Vadym Mukhin, Yaroslav Kornaga, Yaroslav Lavrenko, Oleg Barabash, Oksana Herasymenko, "Analytical Assessment of Security Level of Distributed and Scalable Computer Systems", International Journal of Intelligent Systems and Applications (IJISA), Vol.8, No.12, pp.57-64, 2016. DOI: 10.5815/ijisa.2016.12.0

[15] V. V. Kosenko, N. G. Kuchuk, "Modeling of Technical Information and Telecommunication Network Based on its Particular Implementation of Information", Information Processing Systems, Kharkiv: Ivan Kozhedub Kharkiv National Air Force University, No. 9(146), pp. 167-171, 2016.

[16] V. V. Kosenko, N. G. Kuchuk, "Interaction Hardware and Software While Control Traffic Distribution", Scientific publication "Systems of Arms and Military Equipment", Kharkiv: Ivan Kozhedub Kharkiv National Air Force University, No. 3(47), pp. 72-75, 2016.

[17] V. V. Kosenko, R. V. Artyukh, A. I. Rogovoi, "Variant Structure Hierarchy Synthesis Infocommunication Network", Academic Journal "Control, Navigation and Communication Systems", Poltava National Technical Yuri Kondratyuk University, No. 4 (44), pp. 60-63, 2017.

\section{Authors' Profiles}

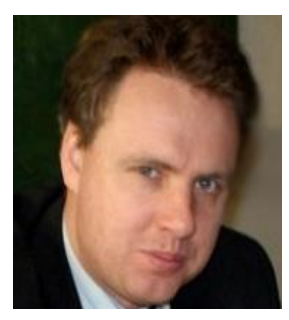

Vadym Mukhin: Professor of department of mathematical methods of system analysis of National Technical University of Ukraine "Kiev Polytechnic Institute", Doct. of Sc.

Born on November 1, 1971. M. Sc. (1994), PhD (1997), Doct. of Sc. (2015) from the National Technical University of Ukraine "Kiev Polytechnic Institute"; Assoc. Prof. (2000), Professor (2015).

Major interest: the security of distributed computer systems and risk analysis; design of the information security systems; mechanisms for the adaptive security control in distributed computing systems; the security policy development for the computer systems and networks.

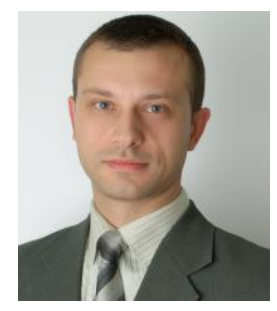

Yury Romanenkov was born in 1977. He graduated from N. Ye. Zhukovsky State Aerospace University "Kharkov Aviation Institute" with a degree in "Automatic control systems for aircrafts and complexes". In 2004, he defended thesis for the degree of Candidate of technical sciences in the specialty "Project management and development of production", in 2017 he defended thesis for the degree of Doctor of Technical Sciences in the specialty "Information Technology" in N. Ye.Zhukovsky National Aerospace University "Kharkov Aviation Institute" (Kharkov, Ukraine). From 2000 to the present time he worked as an assistant and an assistant professor; he currently holds a professorship at the Department of Management in N. Ye. Zhukovsky National Aerospace University. "Kharkiv Aviation Institute". He is the author of more than 100 scientific publications. His scientific interests lie in the fields of modelling and forecasting in organizational and technical systems.

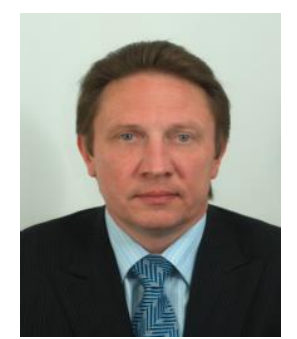

Victor Kosenko was born in $1960 . \mathrm{He}$ graduated from Kharkov State University of Economics and got a degree in Industrial Management. In 2003 he defended his thesis for the degree of candidate of technical sciences, the specialty is "Automated control systems and innovative information technologies". From 2006 till 2010 he worked as the deputy director for scientific work at Kharkiv Scientific and Research Institute of Mechanical Engineering Technology, since 2010 he has held the post of the director of Kharkiv Scientific and Research Institute of Mechanical Engineering Technology. He is the author of more than one hundred scientific publications. $\mathrm{He}$ is a corresponding member of the Engineering Academy of Sciences of Ukraine. His scientific interests lie in the field of management systems and information technologies. 


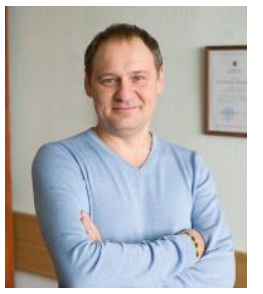

Anton Rohovyi was born in 1973. He graduated from Kharkov State Polytechnic University with a degree in Computerized Information Processing and Control Systems. In 2000, he defended his thesis for the degree of candidate of technical sciences on the specialty "Automated control systems and advanced information technologies" in National Technical University "Kharkiv Polytechnic Institute" (Kharkiv, Ukraine).

From 2000 to the present time he worked as an assistant and currently works as an associate professor at the Strategic Management Department of National Technical University "Kharkiv Polytechnic Institute". He is the author of more than 30 scientific publications. Scientific interests - project management, modeling of complex systems development, big data.

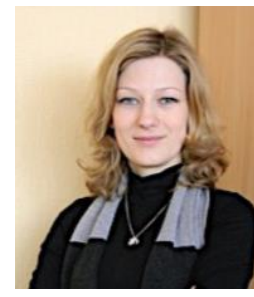

Anna Kharazii was born in 1984. She graduated from National Technical University "Kharkiv Polytechnic Institute", specializing in Project Management. In 2016 she defended her thesis for the degree of candidate of technical sciences on the specialty "Management of Projects and Programs" in O.M.Beketov National University of Urban Economy (Kharkiv,

Ukraine).

From 2007 to the present time she worked as a technician, engineer, senior engineer and currently works as an assistant at the Strategic Management Department National Technical University "Kharkiv Polytechnic Institute".

She has 13 scientific publications. Scientific interests - IT project management, IT project management methodology, analysis of big data.

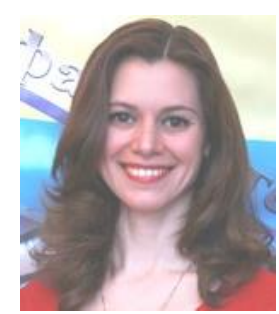

Julia Bilokin was born in 1984. She pursued her Master's degree in Safety Management at National Aerospace University "Kharkiv Aviation Institute", Kharkiv, Ukraine in 2007. She obtained the $\mathrm{Ph}$. D. degree in Project and Program Management from National Aerospace University "Kharkiv Aviation Institute" in 2011. She is currently working as Associate Professor at the Department of Information Control Systems, National Aerospace University "Kharkiv Aviation Institute". She has published various research papers in international and national journals and conferences. Her research interest focuses on Project and Program Management, Life Cycle Management and Structural Analysis.

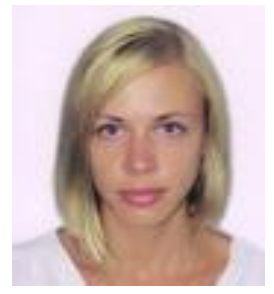

Natalia Kosenko was born in 1981. She graduated from N. Ye. Zhukovsky National Aerospace University "Kharkov Aviation Institute" and got a degree in "Project Management". In 2015 she defended her thesis for the degree of Candidate of Technical Sciences in specialty "Project and Program Management".

From 2009 to 2014 she worked as an assistant at the Department of Management of N. Ye. Zhukovsky National Aerospace University "Kharkiv Aviation Institute". From 2014 to 2015 she occupied a position of Junior Researcher of the Department of Technology and Automation of Production of Radioelectronic and Electronic Computing Means in Kharkov National University of Radio Electronics. Since 2015 she has been working as Associate Professor at the Department of Project Management in the Urban Economy and Construction in A. N. Beketov Kharkiv National University of Municipal Economy. She is the author of more than thirty scientific publications. Her scientific interests lie in the sphere of project and program management as well as in the management of project human resources.

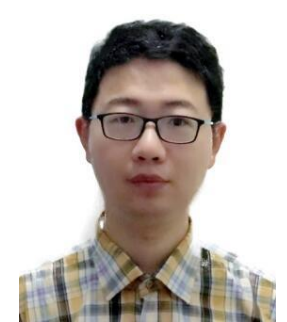

Su Jun: PhD, Associate Professor of School of Computer Science, Hubei University of Technology. He received Ph.D. degree in Computer Systems and Components from Ternopil National Economic University, Ternopil, Ukraine in 2013. He has published more than ten papers in the area of Computer Network and wireless communication. His research interests include Wireless Sensor Network, Selforganizing network technology, Wave propagation and electromagnetic interference. Dr. Su is a member of IEEE and ACM.

How to cite this paper: Vadym Mukhin, Yury Romanenkov, Julia Bilokin, Anton Rohovyi, Anna Kharazii, Viktor Kosenko, Nataliia Kosenko, Jun Su, "The Method of Variant Synthesis of Information and Communication Network Structures on the Basis of the Graph and Set-Theoretical Models", International Journal of Intelligent Systems and Applications(IJISA), Vol.9, No.11, pp.42-51, 2017. DOI: 10.5815/ijisa.2017.11.06 